\title{
A Educação Moral e Cívica na construção de ser brasileiro: Um indi- víduo obediente, cristão e anticomunista
}

\author{
The Moral and Civic Education in the construction to be Brazilian: An obedient christian individual \\ and anticommunist
}

\author{
Catia Maria da Silva*, Maria Elisa Carvalho Bartholo
}

\begin{abstract}
Resumo
Como citar esse artigo. da Silva, C.M.; Bartholo, M.E.C. A educação moral e Cívica na construção de ser brasileiro: Um indivíduo obediente, cristão e anticomunista. Revista Mosaico. 2017 Jan./Jun.; 08 (1): 23-31.

O anticomunismo no Brasil foi o palco onde tanto os políticos quanto os civis da década de 60, tiveram que atuar. Estudantes e trabalhadores levados pelas condições sociais viam nas propostas comunistas uma possibilidade para uma vida menos árdua. Ações e ideais anticomunistas se fizeram presente desde a década de 20 no Brasil, porém, é a partir da revolução de Cuba, com a política interna de autossuficiência e uma não dependência dos Estados Unidos da América (E.U.A), que a sociedade brasileira vê um perigo real, devido à proximidade do novo país socialista. E é nesse cenário de Guerra Fria e lutas ideológicas que Jânio Quadros renuncia à presidência do Brasil e cede espaço a João Goulart, então vice-presidente. Foi sob uma intensa desconfiança nas ações políticas do então presidente Goulart, que decide por dar continuidade à política de não dependência aos E.U.A e sua aproximação dos países socialistas, que se tem o desfecho do golpe civil militar em 1964. Golpe planejado pelas forças armadas brasileiras, mas que encontrou apoio na população civil do país. Tendo como base a Doutrina de Segurança Nacional, o regime militar buscou reorganizar algumas instituições nacionais e uma delas foi a educacional. Através do decreto-lei n 869 de 12 de setembro de 1969 , que tornou obrigatório o ensino da disciplina de Educação Moral e Cívica (EMC) em todos os anos escolares. Disciplina imposta pelo regime e que tinha um único objetivo, o de incutir no indivíduo uma moral do cidadão ao mesmo tempo em que combatia o que se entende como o "perigo vermelho".

Palavras-Chave: Educação; Brasil República; História Política.
\end{abstract}

\begin{abstract}
O Anticommunism in Brazil was the scene where both, politicians and civilians from the 60, had to act. Students and workers led by social conditions saw the communists proposed a possibility for a less strenuous life. Actions and ideas anticommunist were present since the 20 in Brazil, but is from the revolution in Cuba with the internal policy of selfsufficient and non proximity of the new socialist country. And it's this cold war scenario and ideological struggles that Jânio Quadros resigns the presidency of Brazil and gives then the policy actions to president Goulart, who decides for the continuity to the policy of non-Us dependency and its approach of the socialist countries, which have the outcome of the civil-military coup in 1964. The coup was planned by the Brazilian armed forces, but found support in the country's civilian population. Based on the doctrine of national security, the military regime sought to reorganize some national institutions and one of them was educational. By decree-law No. 869 of 12 September 1969, which made compulsory the teaching of the (EMC) discipline in all school years. Discipline imposed by the regime and who had one goal, to instill from the individual one moral of citizen at the same time fighting the "red danger".

Keywords: Education; Brazil Republic; Political history.
\end{abstract}

\section{Introdução}

O ideário anticomunista no Brasil recebeu desde sua origem, forte influência externa, principalmente dos Estados Unidos da América (E.U.A) que na defesa do regime econômico liberal/capitalista tomou frente na luta contra o avanço dos ideais comunistas nos países europeus e nos países subdesenvolvidos. Fazendo uso de sua ainda nascente, porém já forte influência sobre outros territórios, o anticomunismo norte-americano buscou direcionar o olhar dos países da América Latina contra o perigo vermelho ${ }^{1}$. Apesar de toda a influência e pressão feita pelos E.U.A no Brasil, o anticomunismo teve como base a tradição católica, o patriotismo e também a elite empresarial

Afiliação dos autores: † Graduada em História pela Universidade Severino Sombra, USS;

\$ Professora da Universidade Severino Sombra, USS.

*ctmaria205@gmail.com 
brasileira que via nas propostas do inimigo um perigo aos seus empreendimentos e posição social.

Aspectos da formação cultural do povo brasileiro, ações e ideais anticomunistas se fizeram presentes desde a década de 20 no Brasil, porém, é a partir da revolução de Cuba, com política interna de autossuficiência e uma não dependência aos E.U.A, que a sociedade brasileira concebe um perigo real devido a proximidade do novo país socialista. E é nesse cenário de guerra fria e lutas ideológicas que Jânio Quadros renuncia à presidência em agosto de 1961, ocupando seu lugar o então vice-presidente João Goulart que, em eleições anteriores, havia recebido apoio dos comunistas, fato que era do conhecimento de todos. Sua simpatia pelos ideais socialistas levou a temores quanto à possibilidade de se ter uma infiltração comunista nas bases políticas do país, fazendo com que a classe política se manifestase contra a posse de Goulart. Imposição que só foi amenizada por meio de remanejamento de poderes do Executivo. Foi sob uma intensa desconfiança nas ações políticas do então presidente Goulart, que se dá o golpe civil militar em 1964. Golpe planejado pelas forças armadas, mas que encontrou apoio na população civil do Brasil.

Permanecendo no poder por um período de 21 anos, tempo em que, em um primeiro momento puderam contar com o apoio de uma parcela significativa da população, os militares no poder atuaram sob diversas instituições sociais. Essa atuação, nos setores estruturais da sociedade, tinha o objetivo de promover a "segurança interna" ${ }^{2}$.

Levados por uma forte noção de segurança interna, uma das modificações realizadas pelo regime militar, que por sua extensão e amplitude, deixou marcas que podem ser sentidas mesmo após 50 anos de redemocratização do país, em especial pode ser verificada no ambiente educacional. A cisão com a educação que vigorava no período, e a implantação da ideologia de segurança nacional se deu através do Decreto-Lei n ${ }^{\circ} 869$ de 12 de setembro de $1969^{3}$, onde, os ministros da Marinha de Guerra, do Exército e da Aeronáutica militar, decretaram a obrigatoriedade do ensino de Educação Moral e Cívica no $1^{\circ}$ e $2^{\circ}$ graus (atuais Ensinos Fundamental e Médio). A necessidade de se implementar a Doutrina de Segurança Nacional, difundida no âmbito da Guerra Fria na década de 1950 pelo EUA e readaptada no Brasil à noção geopolítica nacional, por um dos principais formuladores da Doutrina de Segurança Nacional da Escola Superior de Guerra (ESG), o General Golbery do Couto e Silva, está ligada, segundo a visão do regime militar, à eliminação do inimigo interno ${ }^{4}$, por meio, não só da perseguição e prisão dos inimigos, mas também pela exaltação do amor apátria, aos símbolos nacionais e da valorização da família brasileira.
A inserção do ensino de EMC nos currículos escolares, não se deu apenas, como uma prática educacional, mas sim como uma disciplina com conteúdos a serem ensinados em todos os anos do ensino. Em sua tese sobre "O regime militar no livro didático de história do ensino médio: A construção de uma memória," Rodrigues (2004 citado por Rocha, 2008), que afirma que:

"A disciplina de Educação Moral e Cívica representa uma
ruptura com a forma da disciplina e com os conteúdos
anteriormente ensinados. Tal tese não se sustenta,
pois seus ensinamentos, portadores de forte carga
ideológica, caracterizaram-se por estimular a formação
de um homem pacífico, moralmente correto, patriota,
um cidadão súdito. O propósito de inclusão da Educação
Moral e Cívica seria, sinteticamente, a incorporação de
seus ideais à sociedade, perpassando gerações, e isto
deveria realizar-se como o próprio saber. A finalidade da
Educação Moral e Cívica seria de preparar o homem para
a vida, e, sobretudo formar o cidadão para a sociedade
de acordo com as proposições do decreto que a criou".

De acordo com Rodrigues, a inserção do ensino de EMC, longe de se apresentar como uma ruptura ao ensino de história atende aos ideais nacionalistas da elite político-militar brasileira.

Se a criação e condução de uma história do Brasil estiveram como principal objetivo da disciplina de história, e estando o foco da EMC na orientação e formação de cidadãos patriotas - indivíduos disciplinados pelo decreto, conscientes de suas obrigações para com a pátria, fica claro que o ensino da EMC atende ou dá prosseguimento a ideologias já conhecidas pela cultura política brasileira.

Na mesma tese, é citado Fonseca ${ }^{6}$ (2004, p. 21), que esclarece:

"A formação moral e a transmissão de valores sempre
estiveram presentes na educação brasileira, porém a
forma de transmitir isso e a concepção acerca desses
valores tem variado segundo o contexto sociopolítico
e as forças sociais dominantes no país. Com o golpe
militar de 1964 , o Estado passa a se preocupar com
a necessidade de revigorar o ensino de educação
cívica pela ótica da doutrina de segurança nacional,
havendo como contrapartida, a descaracterização e
o esvaziamento do ensino de história nas escolas."

Há, nesse momento, não só uma modificação nos conteúdos da disciplina de história, como também uma redução na carga horária de ensino e uma perda da autonomia dos professores de Humanas,essa perda de espaço que não só os conteúdos, mas também os docentes da disciplina sofreram a partir da vigência da lei $\mathrm{n}^{\mathrm{o}} 869$, descaracterizou todo o ensino no Brasil. Mas que a redução na carga horária no ensino, a disciplina história e os professores, tiveram como substitutos os livros didáticos de EMC, que levavam para a sala de aula ideologias políticas visando a 
construção de cidadãos compromissados com a Pátria, como também a elaboração de uma "história" brasileira.

Bittencourt (2003 citado por ROCHA, 2008, p. 185), afirma que o ensino de História, desde sua inclusão no plano de estudos do colégio Pedro II:

"Está associado, inevitavelmente, à constituição da identidade nacional. Nacionalismo patriótico, cultos a heróis nacionais e festas cívicas são alguns valores que, na escola, se integram ao ensino da história do Brasil ou, ao menos, de certa história do Brasil."

Um olhar mais atento à história da História no Brasil permite constatar que se buscou incutir valores nacionalistas, morais e cívicos à sociedade, visando à construção de uma história própria, ou seja, uma genealogia da nação?. A "criação de uma Memória Nacional que exalte o país por sua própria cultura e os feitos de seus "heróis"'. Contudo, foi a partir da proximidade do perigo vermelho e principalmente com a revolução cubana, que no período acreditavase ter trazido para mais perto o comunismo, que se intensificaram não só o "imaginário anticomunista", mas também, as ações anticomunistas da sociedade brasileira. E uma dessas ações está presente na formação do ser (indivíduo) pelo livro de EMC adotado em todos os anos escolares.

Sendo o livro didático uma ferramenta de apoio no processo de ensino aquisição de saberes, suporte com fontes e interpretações históricas e a aproximação dos alunos de métodos que podem ser utilizados em outros contextos -, ao ser utilizado como guia inquestionável, pois seus conteúdos eram apresentados como verdades históricas, o papel do docente em sala passa a ser apenas o de um auxiliador na reprodução do conhecimento apresentado.

Diante da importância que o livro didático possui no processo educativo como ferramenta de apoio na organização e condução do desenvolvimento do aluno ${ }^{9}$, o livro didático vai além de um mero material de apoio, ele é um objeto cultural. É o principal uniformizador dos saberes selecionados, se tornando um meio eficaz de se conduzir a uma massificação cultural. Estando como difusor dos programas curriculares, o livro didático expressa a ideologia política dominante, ou seja, durante e por meio do processo educativo, o livro didático incuti não só saber como conhecimentos específicos para a vida em sociedade e o mercado profissional, mas também formar pensamentos político-ideológicas. Assim, esse artigo, busca identificar em alguns livros didáticos de EMC, como se deu a construção do ideal cívico que tinha como intenção promover os ideais nacionalistas e anticomunistas.

Buscando meios diversos para identificar os possíveis subversivos, que agora não vinham mais de fora, mas se encontravam alastrados pelo país, no seio da sociedade, e com a intenção de proteger a Nação dos males que o comunismo poderia causar ao Brasil, a Doutrina de Segurança Nacional foi repensada e adaptada em conteúdos formais de cunho escolar, tendo como foco a EMC do povo brasileiro. Para a construção desses indivíduos - cidadãos foram utilizados mais intensamente três bases da cultura brasileira: a religião/catolicismo, o nacionalismo e o liberalismo.

Utilizando como fontes, três livros didáticos de Educação Moral e Cívica, e delimitando o período adotado nas escolas entre os anos 1969-1985, apesar de a obrigatoriedade do ensino de EMC ter sido revogada apenas oito anos mais tarde - por meio da Lei $\mathrm{n}^{\circ} 8.663$, de 14 de junho de $1993^{10}$.

A doutrina nacionalista de exaltação à Pátria pode ser verificada em períodos anteriores ao regime militar de 1964.No entanto, é no período de vigência da ditadura militar que essa ideologia toma formas mais abrangentes e um direcionamento.

A Comissão Nacional de Moral e Civismo juntamente com o Conselho Federal de Educação (CNMC/CFE), como órgãos reguladores $\mathrm{e}$ direcionadores do discurso cívico, influenciaram diretamente na elaboração dos livros didáticos, legitimando por meio de aprovações os que atendessem suas determinações. O incentivo ou não do uso de determinados livros didáticos, pelas instituições educacionais, teve um peso sobre a forma como esses discursos foram construídos. Dessa forma buscou-se no processo de escolha das fontes, selecionar os livros de EMC que tenham sido certificados pela CNMC/ CFE e ou que atendessem aos princípios da Doutrina de Segurança Nacional.

\section{Discurso anticomunista}

Ao analisar os discursos políticos historicamente produzidos, percebe-se que seu conteúdo muda na proporção que vão se alternando seus formuladores. Assim como os ideólogos se alternam, também se altera suas interpretações sobre o momento político. No Brasil, podemos encontrar essas mudanças político-ideológicas no processo de construção das bases políticas cada qual de acordo com sua cultura e interpretações do cotidiano.

No período que vai da década de 60 a década de 80 , a preocupação dos ideólogos dos discursos políticos, se pautava na defesa do país, contra um perigoso inimigo que, de acordo com o imaginário sociopolítico, se infiltrava na sociedade a partir dos descuidos dos cidadãos brasileiros. Para que um discurso produza o resultado esperado, este deve ser 
pautado a partir das configurações socioculturais de cada momento político do país e, nesse momento, a grande preocupação, era o comunismo. Para o Brasil que se posicionou contra, essa doutrina se constituía em uma filosofia corruptiva para a organização político-social já estabelecida. Diante de tal perigo, diversos setores da sociedade brasileira buscaram construir seu discurso anticomunista, e dentre os discursos elaborados pode-se destacar o de três bases culturais do Brasil: o catolicismo, o nacionalismo e o liberalismo.

O historiador Rodrigo Patto Sá Motta, na tese resultante de sua pesquisa defendida em 2002 na Faculdade de Filosofia, Letras e Ciências Humanas da USP, relacionou os discursos anticomunistas dessas bases culturais. Tendo como uma de suas fontes de análises: Encíclicas elaboradas, no período entre 1878 e 1937, que tratavam do assunto comunismo, destacando-se o fato da Igreja Católica ver o perigo vermelho como mais um de seus inimigos históricos. Devido a sua filosofia ateísta, que buscava dar explicações fora do contexto da Igreja, e por buscar incutir valores que também não se relacionavam com os princípios morais do catolicismo, por incentivar a luta de classes e a tomada do poder pelos trabalhadores por meio da violência e por não buscar resguardar a família como forma de instituição moral.

Diante de todas as propostas comunistas, a destruição da instituição familiar e a negação à existência de Deus, fez ressoar na sociedade brasileira, culturalmente ligada a religiosidade católica, principalmente entre as mulheres, uma barreira anticomunista. A experiência vivida pela Igreja em Moscou - com a perseguição, prisão e execução de autoridades católicas - e a doutrina pregada pelo comunismo foram fatores decisivos na posição da instituição católica, que combatia por diversos ângulos, como: cartas pastorais que versavam sobre o comunismo e que eram lidas para os fiéis durante as missas, os movimentos civis, a participação na política, à organização de corporações cristãs e um dos movimentos anticomunistas mais fortes - a organização feminina anticomunista.A abrangência do anticomunismo católico, como já dito, deveu-se aos conceitos éticos cristãos que a filosofia comunista estaria destruindo se consolidada, princípios passados e mantidos na sociedade brasileira pela instituição católica. A observação da boa conduta moral pautada no cristianismo era o principal combustível do discurso anticomunista católico, porem não só utilizado por essa instituição, a atenção para a boa conduta moral dos brasileiros também podia ser observado no discurso nacionalista ${ }^{11}$. Para os patriotas, o comunismo vinha subverter os princípios nacionais e desestruturar a ordem estabelecida na sociedade. Os nacionalistas defendiam a ideia de nação acima de tudo. Para eles, assim como para a Igreja, o comunismo tinha como objetivo dividir o povo incentivando divergências entre as classes sociais, o que causaria a destruição do povo brasileiro. $\mathrm{O}$ incentivo ao patriotismo era uma das funções do discurso anticomunista de base nacionalista, que tentava insuflar ou resgatar no povo um sentimento de nacionalidade, nesse âmbito, pode-se identificar outro encontro entre as falas da instituição católica e a dos nacionalistas. Os nacionalistas questionavam a destruição por parte do comunismo da boa conduta moral observada e conduzida pelos princípios católicos, do bom comportamento civil por meio do cumprimento dos deveres sociais de cada um e obediência às leis e o amor à Pátria. Em seu texto sobre "Matrizes do Anticomunismo", Motta (2002) afirma que:

“A nação ${ }^{12}$, o conjunto formado pelo povo brasileiro unido ao território e ao Estado, seria intocável, ou seja, mereceria a aura de objeto sagrado. Nesse sentido os comunistas seriam elementos, 'deletérios', pois instigavam a divisão e a própria destruição do 'corpo' nacional, à medida que insuflavam o ódio entre as classes."

Concepção de nacionalismo que foi fortemente influenciada pelo romantismo alemão.

Já para o anticomunismo liberal, o comunismo destruiria a liberdade econômica e política, por meio da destruição do direito à propriedade e existência de partidos políticos. No entanto, o anticomunismo com base nos preceitos liberalistas foi utilizado de forma cautelosa, pois, apesar de o discurso anticomunista liberal enfatizar o caráter autoritário e antidemocrático do comunismo, no Brasil, a tradição política era de governos autoritários, fato que limitava a produção de um discurso anticomunista pautado na liberdade democrática.

O liberalismo que foi assimilado pela cultura política conservadora brasileira, buscava ampliar os direitos políticos e de aquisição e manutenção das propriedades privadas, porém essas ampliações eram realizadas de forma que não abrangessem as classes subalternas. Mantendo assim, uma organização social brasileira pautada sob a manutenção de privilégios.

Entre essas três bases culturais o maior ponto de encontro foi à construção do imaginário anticomunista, muitas vezes um imaginário carregado de exageros difundidos entre a sociedade.

\section{Fontes e apresentação dos livros}

Mauad e Cardoso (1997, p. 401), em um texto sobre o início do uso de imagens na História, citando a história da arte, mas tendo como enfoque a fotografia 
e o cinema, destacam o convite de Marc Bloch e Lucien Frebvre, fundadores da Escola dos Annales, aos historiadores para saírem de seus gabinetes e buscarem vestígios da ação humana em outros tipos de fontes. 403),

Ainda segundo Mauad e Cardoso (1997, p.

"Muito se tem feito, em matéria de estudo de imagens, (...) No entanto, o verdadeiro ponto de partida, no tocante as imagens vistas em perspectiva semiótica, é a noção de ícone avançada por Charles SandersPeirce e, em seguida, as críticas de que foi objeto. Para Peirce, um ícone "e um signo que se refere ao Objeto que denota simplesmente por força de caracteres próprios (...) que ele possuiria”.

Para esclarecer o que foi citado acima, Mauad e Cardoso (1997, p. 403), afirmam que "os signos icônicos seriam imediatamente comunicativos por serem de percepção instantânea."

Norbert Elias (1994, p. 17), em sua obra o Processo Civilizador, busca entender os significados dos conceitos cultura e civilização nas sociedades francesa e alemã, "investigando a sociogênese do Estado, onde cita entre um dos aspectos da história da formação e estrutura deste, o problema do 'monopólio da força"”.

Ainda segundo Elias (1994, p. 24),

"A palavra alemã kultiviert (cultivado) aproximase muito do conceito ocidental de civilização. (...). Tal como a palavra 'civilizado', kultiviert refere-se primariamente a forma da conduta ou comportamento da pessoa. Descreve a qualidade social das pessoas, suas habitações, suas maneiras, sua fala, suas roupas (...)".

Em nosso trabalho, o Estado através dos livros de EMC e das imagens e textos apresentados neles, buscava cultivar o tipo ideal de cidadão civilizado, para a sociedade brasileira, com o intuito de proteger a família brasileira da ideologia comunista.

A observação das fontes foi realizada em dois momentos distintos, embora fossem interligados. Primeiro, com o objetivo de conhecer os livros didáticos a serem trabalhados, buscou-se observar: Qual a figura o livro didático traz em sua capa, se desenho ou imagem fotográfica? Quantas páginas ele possui? Quantos capítulos? Quantas vezes o tema anticomunista aparece? Se o autor (a) faz uso de exercícios ou somente leitura? A que se destinam esses exercícios, a memorização ou se há um questionamento do tema?

Analisando os livros didáticos de EMC, buscase observar como o livro se apresenta em seu exterior - pois estes são destinados a $4^{\circ}$ série do ensino primário e ao curso de admissão - , se o mesmo traz já em sua capa representações que expressem o ideal do momento político. Verifica-se que o livro de autoria de
Flávio A. Pereira, fonte (A), que se encontra em sua terceira edição no ano de 1971, contendo 91 páginas, traz na capa a imagem fotográfica da escola Gabriel Soares de Souza, nome que prestigia um historiador português do século XVI, um dos primeiros escritores a escrever sobre o Brasil, escola que se localizava em Realengo. Além da imagem da escola sua capa apresenta o nome da editora, estado de edição e a que ano escolar se dedica, que nesse caso $4^{\mathrm{a}}$ série primária e curso de admissão.

A fonte (A) se constitui em um livro com uma vasta escrita que apesar de se destinar também aos discentes da $4^{\mathrm{a}}$ série do Ensino Primário, a abordagem dos temas nele trabalhado foram elaboradas de forma dura, ou seja, se buscou objetividade tanto no conteúdo escrito quanto nas imagens representativas.

Nas primeiras páginas, podemos encontrar, além do índice onde se identificam os temas de interesse do presente trabalho - A família e a escola; Os símbolos Nacionais; O Estado; As forças Armadas; Os ideais de vida; A História Pátria; Calendário Cívico e Hinos Patrióticos -, uma pequena carta de apresentação direcionada aos professores, onde é ressaltada a obrigatoriedade do ensino da Educação Moral e Cívica, decretado pela Lei no 869 de 1969. Logo em seguida, o autor apresenta "O que é Educação Moral e Cívica?".

O livro (A) se caracteriza por uma abordagem voltada mais para o desenvolvimento de um sentimento de nacionalismo e conhecimento das bases econômicas do País, dedicando pouco espaço ao tema religião, contudo sem deixar de no decorrer do livro trabalhar a moral e a ética do cidadão brasileiro. $\mathrm{O}$ autor não utiliza muitos exercícios, podendo ser encontrado no final de alguns capítulos, de 3 a 4 exercícios de fixação e 1 ou 2 de pesquisa.

Diferente da fonte (A) o livro (B) de autoria de Edília Coelho Garcia, publicado em 1972 com 324 páginas, tem uma capa mais próxima do público a que se destina, as escolas de primeiro grau. Tendo como desenho de fundo o sol com três crianças à frente representando o povo brasileiro, um Brasil mestiço uma criança para cada etnia brasileira, um negro,um caucasiano e um indígena. Em sua carta aos docentes, ressalta três pontos importantes ao utilizarem o livro de EMC, anunciam que o livro se destina aos alunos e que reúne assuntos que podem ser ministrados em diversas séries do ensino educacional. Cabendo ao professor a decisão quanto à profundidade da abordagem de tais temas - respeitando as séries em que estará trabalhando. Que o livro oferece aos docentes, ajuda objetiva e que obedece as normas estabelecidas pela CNMC e pelo CFE. Não deixando de destacar o fator formação do ser, pautado na ética a ser conduzida pela criação de bons hábitos a serem desenvolvidos com o auxílio do docente. 
O livro contém 120 subtemas sendo que desse total, 31são de abordagem de cunho religioso e moralista; 57 versam sobre o nacionalismo e 7 são de base liberalista/econômica, chegando ao total de 95 subtemas cujo discursos são de bases anticomunistas. A autora dá preferência a uma abordagem escrita mais próxima da realidade educacional dos alunos da escola de Primeiro Grau. Seu livro faz uso de muitas gravuras coloridas que buscam reforçar sua mensagem escrita. Todo o livro é trabalhado a partir de um personagem principal, uma criança membro do que seria ou deveria ser a família brasileira. O livro não contém exercícios e nem trabalhos de pesquisa, ele tem um programa em suas primeiras páginas onde são passadas aos docentes as orientações para o desenvolvimento dos temas trabalhados.

A fonte (C), de Antônio Xavier Teles, publicado em 1975, com 249 páginas, traz em sua capa a imagem do mapa do Brasil. Sob ela um homem pode-se identificar aqui como uma liderança - e atrás dele um número maior de pessoas pintadas da mesma forma - ou seja, uma uniformização. Há um prefácio, no qual busca salientar o caráter condutor e civilizador - empregado com o sentido de progresso/ desenvolvimento - do ensino Moral e Cívico. E posiciona o ensino de EMC como uma aprendizagem crítica e racional, um propósito de ação em prol da Pátria. Contém uma densa escrita só interrompida por fotocopias que acompanham a abertura de cada capítulo e quadros de exercício que prepara e introduz o tema do capítulo.

\section{A ideologia nas imagens}

Toda imagem traz consigo uma mensagem e sua interpretação deve acompanhar o contexto em que ela estiver inserida. Não poderia ser diferente com imagens ilustrativas nos livros didáticos de EMC. Sendo assim, a leitura que se pode fazer das representações encontradas nas capas dos livros de EMC analisados, deve ser realizada tendo como base: a Ideologia de Segurança Nacional conduzida aos estudantes por meio da EMC. As imagens, mais que ilustrar o que um texto diz, se constituem num próprio texto, onde de acordo com cada situação em que é empregada, representa um discurso, uma ideia.

Começando pelas capas dos livros, a fonte A apresenta a imagem da escola com as crianças uniformizadas à frente dela, como a intenção de passar a visão de um país voltado para a educação, país onde suas crianças se encontram nas escolas, sendo orientadas e preparadas para a participação na vida sócio-política do país. Essa imagem atende aos princípios do regime militar, por estar inserida num momento cujo país buscava incutir a imagem de uma sociedade una e disciplinada. A fotocópia de crianças uniformizadas representa assim, a organização e desenvolvimento educacional do Brasil.

Já na fonte B, a imagem do sol com crianças - cada qual representando sua etnia - a sua frente, pode ser compreendida como dias melhores para a Nação, a certeza de que no Brasil, cujo povo é unido - união demonstrada por meio das crianças oriundas de diferentes povos, porém juntas como um povo só - prospera a paz social, a união de um povo, o povo Brasileiro.

A unidade do povo brasileiro se constituiu num dos pontos mais fortes do discurso anticomunista. Reforça-se que a análise dos livros produzidos num período em que o país esteve sob a governança do regime militar e que as alterações realizadas no sistema educacional foram por meio de decretolei elaborado obedecendo à Ideologia de Segurança Nacional. Pode-se entender o sol como representativo do regime que veio para "salvar" o Brasil do "perigo vermelho" que intencionava e assim o creem, estava se entranhando no país, subvertendo aqueles que não tinham o caráter firme. Tal imagem denotava um novo e melhor futuro para a Nação.

As três crianças - negra, caucasiana e indígena - de mãos dadas expressam mais que um povo unido, mas um povo só sem preconceitos e discriminação, um Brasil mestiço, porém uno.

E por fim, na fonte C, o livro de EMC traz em sua capa um homem à frente de outros homens e sob o mapa do país. Essa imagem é a que menos deixa margens para outras interpretações, o homem acima do mapa do Brasil representa uma liderança que deve ser seguida por todo o povo brasileiro representado pelos indivíduos atrás do líder. $\mathrm{O}$ indivíduo/líder representado na capa é o único que contém um rosto, o que deixa claro que a liderança do país deve ser conhecida-reconhecida e respeitada por toda a Nação e como se disse acima, representada pelos indivíduos desenhados de forma igual, sem rosto e enfileirados. Indivíduos caracterizados da mesma forma, o que remete a uma não individualização do povo brasileiro, mas sim um povo uno, indivisível, juntos pelo Brasil.

As imagens distribuídas ao longo das três fontes não diferem muito entre si quanto às figuras. Nos três livros encontram-se ilustrações/imagens de famílias reunidas, crianças estudando, construções urbanas (grandes prédios), monumentos históricos do país, imagens da bandeira nacional e de brasões. As imagens mais relevantes para o trabalho são as que trazem a ideia de família e reconhecimento dos símbolos nacionais.

A imagem da família se torna importante porque ilustra o que seria a família brasileira, pautada sob a orientação moral cristã da Igreja 
Católica. Muitas dessas imagens trazem cada indivíduo desempenhando uma função, de acordo com o gênero que representa. $O$ que mais uma vez nos leva a interpretar aqui uma condução por parte do Estado, das funções sociais (externo e interno ao lar) que os indivíduos devem desempenhar. Discurso apresentado também pela Igreja e que se vincula ao do regime, que vê na tradicional organização familiar uma das bases de resistência ao comunismo.

As imagens de símbolos nacionais expressam a necessidade que o regime via de incutir no indivíduo o amor à Pátria, o reconhecimento e o respeito aos símbolos nacionais. Buscou-se tornar do conhecimento de cada brasileiro ou indivíduo aqui estabelecido a bandeira, hino e brasão nacional, assim como a disciplina a ser empregada diante de tais símbolos. Tanto quanto na escrita, a repetição de um discurso através de imagens, naturaliza a ideologia que se quer incutir, por exemplo: uma família predominantemente branca, sentada à mesa de jantar, tendo a cabeceira da mesa o chefe da casa (termo utilizado na fonte A), filhos e esposa sentados à sua volta, realizando uma prece antes da refeição.

Claramente a imagem passa a noção de família sendo aquela constituída por indivíduos cristãos, caucasianos cuja divisão de tarefas segue a tradicional manutenção do lar realizada pela mulher e o provento deste pelo chefe da casa.

Longe de representar apenas uma simples família brasileira em seu momento de alimentação, a imagem reforça não só o conceito de família, sendo aquela pertencente a classe média brasileira que, de acordo com os temores da Igreja e da própria classe, a organização familiar brasileira deveria ser protegida, assim como proteger a si própria das intenções comunistas. De fato, como se tem ciência e de acordo com os registros, a tradicional família brasileira se constituiu numa das mais fortes barreiras encontradas pelos comunistas e sua ideologia que aqui chegaram. A tradição católica, que no Brasil pode ser encontrada nas bases da formação da sociedade brasileira, orientando as famílias quanto ao perigo vermelho e posicionando o comunismo como inimigo da Igreja por seu ateísmo, sua tentativa de eliminar tanto a Igreja quanto a instituição familiar, de desestruturar a organização social brasileira orientada e reforçada pela Igreja Católica, juntamente com o temor que os nacionalistas tinham de ver o país submetido às propostas socialistas e ter toda a tradição descaracterizada ou eliminada por esse ideal, assim como ter o território nacional dividido ou ocupado de acordo com os interesses comunistas. Enfim, todo o discurso anticomunista produzido pelas bases católica, nacional e liberal pode ser encontrado nos livros de EMC representados nas imagens. O que reforça a compreensão de que mais que combater o inimigo, o Estado pretendia formatar/conduzir a sociedade brasileira através de representações do que ou de como ela deveria ser.

\section{Subtemas}

Não deixando de abordar determinados temas nos livros didáticos de EMC - até por que a aprovação do livro estava diretamente ligada aos temas morais e cívicos - os autores gozavam de certa liberdade quanto à metodologia a ser utilizada na condução dos conteúdos. Pode-se encontrar nas três fontes temas como: família, escola, ética, consciência moral/ valores permanentes, deveres e direitos, religião e símbolos nacionais. Temas que, apesar de terem sido trabalhados de diferentes formas, não diferiram quanto à sutileza na abordagem dos conteúdos, estes, estão interligados de tal forma que ao falar sobre família (fonte A) os autores já ressaltam a organização, obediência e disciplina que toda família deve apresentar. Isso é construído a partir da apresentação da função de cada indivíduo que constitui a família, ou então (fonte $\mathrm{C}$ ) a instituição familiar é apresentada ainda em sua constituição, onde se pode verificar a definição de família sendo aquela formada por um homem e uma mulher que se casam e tem filho(s). Partindo desse modelo nuclear de família, onde se coloca a instituição familiar como exemplo de organização e disciplina, assim como orientadora e condutora da boa conduta moral cristã, as três fontes ampliam esse modelo de organização familiar, ao espaço social inserindo a escola como um espaço cujo ambiente exige do discente um comportamento disciplinar igual ao que ele deve ter no lar.

A preocupação do regime militar em modelar a sociedade brasileira - ação que para os militares resultaria em dois objetivos alcançados, o de tornar o povo brasileiro obediente, ou seja, por meio de orientações quanto ao comportamento que se espera que um cidadão brasileiro tenha e moldá-los de tal forma que, uma vez assimilada às determinações quanto à conduta de um bom cidadão, este se torne obediente e cumpridor dos seus deveres. E o outro corresponderia de acordo com as justificativas das forças armadas brasileira para terem assumido o governo do país - o combate ao comunismo. Partindo do princípio de que o golpe militar foi arquitetado e executado com a única intenção de proteger o país da subversão comunista, deve-se pensar que todo o esforço empregado no sentido de civilizar/disciplinar a sociedade brasileira e enaltecer a Pátria, também se deu com essa intenção.

É bem essa intenção de modelar a sociedade brasileira ao mesmo tempo em que se combate o comunismo, que pode-se verificar nos livros de EMC. 
Por meio de lições sobre como se portar no dia a dia, ou seja, no lar ou fora dele, orientações que invadem e determinam como deve se dar a interação entre os familiares e destes com a sociedade.

A obediência às leis é trabalhada de forma ascendente, se insere a observação à boa conduta e a obediência no lar expandindo esse comportamento para a escola e sociedade no geral e a partir disso se trabalha a conduta moral do bom cidadão.

Já os temas ligados ao reconhecimento e respeito aos símbolos nacionais, são trabalhados ao longo dos capítulos ou no final do livro o que reforça a percepção de que organização estrutural do livro de EMC ficou por conta da forma de trabalhar de cada autor, contanto que seguissem nos conteúdos inseridos, as determinações da CNMC e do CFE. Reconhecer o brasão nacional, a bandeira e saber cantar o hino era o mínimo esperado de um cidadão brasileiro, de um indivíduo que ama a sua Pátria e a conhece. $\mathrm{O}$ amor à Pátria era ressaltado também através do enfoque em personagens históricos, onde se buscava construir uma História do Brasil repleta de indivíduos que lutaram pela defesa do país, seja pela sua independência e para isso a figura mais usada é a de Tiradentes ou pela defesa dos princípios (hábitos e costumes) do país.

No ensino da disciplina de EMC, o discurso anticomunista é exatamente o discurso moralista, nacionalista e liberal. $\mathrm{O}$ anticomunismo nos livros didáticos de Educação Moral e Cívica, não se deu de forma abrupta, de forma que se ponha em destaque o comunismo para combatê-lo por meio das lições cívicas, pelo contrário o comunismo ou era citado num pequeno trecho ou não o era. Porém, o combatiam a todo o tempo quando se buscava fortalecer o sentimento de se pertencer, de se fazer parte de um povo, o povo brasileiro. Ao se ressaltar a tradição católica da população brasileira e fazer uso da religiosidade desta para se incentivar e definir o caráter do bom cidadão, assim como o uso do crescimento econômico do país como consequência e dependente do cumprimento dos deveres socioeconômicos de cada brasileiro.

Essa estratégia de combate ao comunismo por meio do fortalecimento dos princípios $\mathrm{e}$ costumes nacionais, que utilizou o espaço escolar e sua estrutura organizacional para efetivação dos programas civilizadores com base na Doutrina de Segurança Nacional e combate ao inimigo interno, foi possível por ter sido realizada de forma incisiva - a obrigatoriedade do ensino de EMC em todos os anos escolares -, e por ter encontrado na sociedade brasileira um apoio na luta anticomunista, seja através dos conselhos transmitidos nas missas, pelos padres; nas campanhas realizadas pelas mulheres da classe media brasileira, em prol de família; pelos discursos com base liberal, expostos em jornais ou revistas ou ainda nas explanações de exaltação à Pátria. $\mathrm{O}$ posicionamento anticomunista que parte significativa da sociedade brasileira apresentava, só auxiliou na condução da disciplina de EMC, uma vez que reforçava os discursos apresentados pela disciplina cívica.

Considerando todo o imaginário anticomunista que vigorava na sociedade brasileira naquele período, e que era reforçada pelas mídias, livros e políticos conservadores em seus discursos inflamados, podemos perceber o quão propício era o ambiente social brasileiro para a modelagem - pelo regime militar - do ser brasileiro.

\section{Conclusão}

Concluímos que o discurso anticomunista foi - inserido nos livros didáticos de EMC, através da valorização dos costumes brasileiros. Em outras palavras, o discurso anticomunista que norteou o ensino de EMC se constituiu a partir de bases culturais da sociedade, fazendo uso dessas bases - religiosa, nacional e liberal - de forma sutil e incisiva se buscou organizar a população lhes incutindo a noção do que é ser um bom cidadão, quais os deveres desse cidadão modelo que uma vez disciplinado e religioso se torna um exemplo de bons hábitos e costumes morais e éticos, e que na defesa do regime político e econômico de seu país procura cumprir com suas obrigações nacionais. Esse cidadão que se almejava construir a partir do ensino da Educação Moral e Cívica, levado pela estrutura de sua formação moral nacionalista, seria um cidadão anticomunista, leal à sua Pátria e um defensor da estrutura social brasileira. Cabe ressaltar em nossa conclusão que, em termos de objetivos alcançados, podemos dizer que o ensino de EMC alcançou de forma expressiva se considerarmos que ainda hoje encontramos indivíduos que receberam em sua formação tal instrução educacional e que a defendem como o caminho para se solucionar as questões sociais de hoje. Não cabe aqui dizer se está ou não correto o posicionamento dos defensores do ensino de EMC, contudo essa assimilação foi possível por ter sido realizada pela instituição familiar, o que veio a reforçar os conteúdos morais e cívicos passados nos ambientes escolares.

No processo de desenvolvimento deste trabalho, nos deparamos com possíveis caminhos de pesquisas a serem realizadas. Partindo da análise dos discursos anticomunistas inseridos nas bases culturais da sociedade brasileira (católica, nacional e liberal), uma das possíveis vertentes a ser aprofundada pode ser, por exemplo: como o discurso das três bases culturais, durante a vigência do regime civil-militar 
(1964-1985), se posiciona diante da questão racial e homossexual? E sobre como o ensino de EMC influenciou a formação política dos estudantes que tiveram em todo o seu período escolar tal ensino?

\section{Notas}

1. Na tese apresentada à Faculdade de Filosofia, Letras e Ciências Humanas para a obtenção do título de Doutor em História econômica, 2000. "Em guarda contra o perigo vermelho", Rodrigo Patto Sá Motta ao longo de seu trabalho vai definindo o termo "perigo vermelho" como uma ameaça cada vez mais real (para os anticomunistas) de uma modificação na estrutura social e econômica do Brasil -se alterando a organização social/regime político/manifestação religiosa e cultural- por meio da infiltração comunista no país.

2. O conceito de Segurança Interna está relacionado com todas as ações do Estado no combate aos antagonismos que ameacem os poderes constituídos do país. Ver as definições de Maria Helena Moreira Alvez: O Estado e Oposição no Brasil, 2005. Bauru SP. Edusc, p. 47

3. Ver em: http: //www2. camara.leg.br/legin/fed/declei/1960-1969/ decreto-lei896-12-setembro-1969-375468-publicacaooriginal-1pe. html. Acesso 20 AGO 2015.

4. O termo "inimigo Interno" está diretamente relacionado ao conceito de Guerra Revolucionária, definido no manual da ESG como: conflito, normalmente interno, estimulado ou auxiliado do exterior inspirado geralmente em uma ideologia, e que visa à conquista do poder pelo controle progressivo da nação. Maria Helena Moreira Alvez: O Estado e Oposição no Brasil, 2005. Bauru SP. Edusc, p. 44, 63-86.

5. De Rodrigues Apud Castilhos, Aristeu Rocha. "O regime militar no livro didático de história do ensino médio: A construção de uma memória” Tese. PUCRS. Porto Alegre, RS, p. 59, 2008.

6. Idem.

7. Ibidem.

8. O imaginário anticomunista é um termo utilizado pelo historiador Rodrigo Patto Sá Motta, em sua tese "Em guarda contra o Perigo Vermelho: o Anticomunismo no Brasil (1917-1964)" defendidana Faculdade de Filosofia, Letras e Ciências Humanas , 2000, USP, para a obtenção do título de Doutor em História Econômica. Para designar o conjunto de imagens produzidas pelos anticomunistas, em torno e sobre a temática "comunismo". A tese foi publicada sobre o título "Em guarda contra o perigo vermelho", em 2002 pela Editora Perspectiva.

9. Rocha, Helenice." A narrativa histórica nos livros didáticos, entre a unidade e a dispersão". Revista Territórios e fronteiras. Cuiabá, vol. 6, n. 3. Dezembro de 2013.

10.http://legis.senado.gov.br/legislacao/ListaTextoIntegral. action?id $=115507 \&$ norma $=137838$

11. O termo nacionalismo aqui utilizado, tem o mesmo sentido definido pelos anticomunistas nacionalistas - eles empregavam a definição do século XIX, a concepção de uma nação una inabalável diante de qualquer conflito social, uma junção orgânica. Motta, Rodrigo Patto Sá, Em guarda contra o perigo vermelho, Matrizes do Anticomunismo, p. 29.
12. Este conceito de nação defendido pelos anticomunistas nacionalistas provém do século XIX, período em que o termo nacionalismo carregava uma noção de corporativismo, entendimento que organizava a nação como um conjunto orgânico.

\section{Referências}

ALVEZ, Maria Helena Moreira. Estado e oposição no Brasil. SP: Bauru. Ed. Edusc, 2005.

ELIAS, Norbert. O Processo Civilizador: Uma história dos costumes. Vol. I. $2^{\text {a }}$ Ed. Rio de Janeiro: Jorge Zahar Editor Ltda., 1994.

GARCIA, Edília Coelho. Educação Moral e Cívica. RJ: Ed. José Olímpio, 1971

MAUAD, Ana Maria e CARDOSO, Ciro F. História e Imagem: Os Exemplos da Fotografia e do Cinema. In CARDOSO, Ciro F. e VAINFAS, Ronaldo (orgs.). Domínios da História: Ensaios de Teoria e Metodologia. $5^{\mathrm{a}}$ ed. Rio de Janeiro: Campus, 1997.

MOTTA, Rodrigo Patto Sá. Em guarda contra o Perigo Vermelho: o Anticomunismo no Brasil (1917-1964)", Tese defendida na Faculdade de Filosofia, Letras e Ciências Humanas - USP, 2000.

. Em guarda contra o perigo vermelho. SP: Ed. Perspectiva. 2002.

PEREIRA, Flávio A. Educação Moral e Cívica. SP: Ed. Livros Irradiantes, 1972

ROCHA, Aristeu Castilhos Da. O regime militar no livro didático de história do ensino médio: a construção de uma memória. Tese de Doutorado defendida na PUCRS em 2008. Disponível em http://meriva. pucrs.br:8080/dspace/handle/10923/3911. Acesso 23 AGO 2015.

ROCHA, Helenice. A narrativa história nos livros didáticos, entre a unidade e a dispersão. Cuiabá: Revista, Territórios e Fronteiras, v. 6, n. 3 , dezembro de 2003.

TELES, Antônio Xavier. Educação Moral e cívica. São Paulo: Ed. Companhia, 1975. 